\title{
Quantitative estimation of 3D cave networks complexity using random walk analysis
}

\author{
Tomasz Błachowicz', Viacheslav Andreychouk ${ }^{2}$ \\ ${ }^{1}$ Institute of Physics - Center for Science and Education, Silesian University of Technology, Gliwice, Poland, \\ tomasz.blachowicz@polsl.pl \\ ${ }^{2}$ Pope John Paul II State School of Higher Education, Biala Podlaska, Poland
}

\begin{abstract}
The paper presents a new method of quantitative parameterization of volumetric-net geomorphological structures with the use of random walk formalism and an analysis of self-similarity exponent distribution derived from random walk experiments. As examples, two American three-dimensional Wind and Lechuguilla cave networks were elaborated. The provided methodology is able to uniquely characterize the morphology of cave systems.
\end{abstract}

Key words: speleomorphogenesis, cave networks, random walk, Hurst exponent, morphometric analysis

\section{Introduction}

It is widely known that geological and geomorphological objects can be treated as fractals (Laverty 1987, Chilès 1988, Feder 1988, Maramathas, Boudouvis 2006). A special place among them occupy the karst and speleological objects (caves) with a complex morphology. In the literature there are only a few studies on this topic (Curl 1986, Laverty 1987, Budge, Sharp 2008, Pardo-Igúzquiza et al. 2012), the authors of which highlight the fractal nature of karst and try to apply some numerical parameters to solve specific problems. Also the authors of this article have taken earlier attempt to determine the fractal characteristics of cave labyrinth in order to assess their morphological complexity (Andreychouk et al. 2013).

While a geometrical fractal can be created using mathematical operations (Mandelbrot, Ness 1968), a fractal character of natural cave systems is weakly predictable (Andreychouk et al. 2013, Curl 1986), since underlying processes of creation are stochastic (Havlin, Ben-Avraham 2002, Pardo-Igúzquiza et al. 2014). From this results a need for quantitative characterization of such geomorphological random phenomena.

In the present paper, we propose a new approach to evaluate the morphological (morphogenetic) complexity of large caves based on a stochastic numerical experiment carried out on digital 3D-models of caves. Performed calculations are parameterized by the so-called self-sim- ilarity exponent distributions. While we do not directly address fractal properties of cave networks, the fractal analysis of caves can be found in our previous work (Andreychouk et al. 2013).

The paper is arranged as follows. At the beginning, after the presentation of investigated cave volumetric networks and after providing some explanations about base geomorphological mechanisms of their origin, a description of a random walk method is given. Next, results of calculations, carried out in the two networks of Wind and Lechuguilla Caves (USA) developed in carbonate rocks, are presented. At the end conclusions are provided.

The Wind and Lechuguilla Caves were chosen for analysis due to their three-dimensionality and huge complexity. It is worth mentioning that the considered caves are hypogene in general (Klimchouk 2007, Klimchouk 2009, Palmer 2011).

\section{Caves}

Analyzed caves are located in the south west of the USA, in the states of South Dakota (Wind Cave) and New Mexico (Lechuguilla Cave). Both caves with their surrounding areas are protected and are the "core" of national parks: Wind Cave National Park, and Carlsbad Caverns National Park, respectively. Both caves are one of the greatest, not only in the USA, but around the World. In the ranking 
of the longest caves presented in 2013, they occupied respectively 6th (Wind Cave, $229.7 \mathrm{~km}$ ) and 7th (Lechuguilla Cave, $222.6 \mathrm{~km}$ ) place (Gulden, 2013).

Both the Wind Cave and Lechuguilla Cave represent themselves extremely complex three-dimensional mazes with a complex geological history ongoing millions of years. These caves were created in hypogenic conditions involving different geological, hydrogeological and hydrogeochemical factors.

Both caves have a significant expansion in vertical direction reaching nearly $220-500 \mathrm{~m}$. In contrast to "flat" cave mazes, developed within a single, horizontal, fissured karst layer (i.e. gypsum cave mazes in Western Ukraine), the characterized caves are complex volumetric labyrinths with morphology controlled by a number of structural-tectonic (slope layers, stratification and lithology) and structural-textural factors.

The Wind Cave system was developed in carbonate rocks, along with a sulphate zone that paralleled the ancient shoreline (Horrocks, Szukalski 2002), in the Black Hills area. Wind Cave is one of the most outstanding examples of multi-storey maze passageways. It extends through some individual limestone and dolomite layers of Mississippian (Carboniferous) age grouped together under the name Pahasapa Limestone. The fissure passages of Wind Cave were developed within the several neighboring layers of carbonate rocks with different lithological properties. Additionally, the fractured layers are not horizontal but are inclined.

The Wind Cave has very long and complex geological history. Its origin is still discussed but in general it is believed that cave was developed gradually in hypogenic conditions with the participation of hydrothermal water (Bakalowicz et. al. 1987, Ford 1989, Palmer 2011).

The Lechuguilla Cave (New Mexico, Guadalupe Mountains) is developed in Permian (Guadeloupian) sediments of the Seven Rivers and Capitan Formations differing by their lithology, mainly in carbonate and siliciclastic beds (limestones and dolostones) (Garber et. al. 1989). Lechuguilla is a hypogenic cave that has been dissolved by sulfuric acid derived from oil and gas accumulations in the Delaware Basin of southeast New Mexico and west Texas (Hill 1987, Palmer, Palmer 2000). Primary porosity in the Capitan and Seven Rivers Formations was a reservoir for water containing hydrogen sulphide, and a pathway for oxygenated meteoric water prior to and during sulfuric acid speleogenesis. Apparently, as is the case of Wind Cave, for the Lechuguilla Cave the stratigraphy-control of passage-orientation takes place (Du Chene, Martinez 2000). Also paleokarst phenomena are widespread in the geological environment of the cave and within the cave.

Unlike the Wind Cave, Lechuguilla has more vertical development. The differences between the highest and lowest parts equals $489 \mathrm{~m}$ (Gulden 2013). The boundaries of caves span the $1.7 \mathrm{~km} \times 2.2 \mathrm{~km} \times 0.2 \mathrm{~km}$ cuboid in the case of Wind Cave and $1.5 \mathrm{~km}$ x $3.3 \mathrm{~km}$ x $0.5 \mathrm{~km}$ cuboid in the case of Lechuguilla Cave. As it was mentioned be- fore, both caves represent morphologically complex volumetric mazes, but differ by their inner morphological structure resulting from geological (structural and stratigraphic) reasons and height of cuboid.

The main goal of the study is an attempt to assess the morphological complexity of the caves, above all, the dependence of their morphology from the structural-geological predispositions (fracturing and stratification of beds and series) and the impact of hydro-geological factors. We assume that the more regular (ordered) character has a morphology of caves, the smaller was the impact of hydrogeological factors, and vice versa. The aim of the simulation was to verify how the mathematical modelling of a random walk type can evaluate the internal morphological diversity of these caves.

\section{Research methodology}

The method of analysis investigates the morphological complexity represented by a cave map (3D model) in a numerical format readable by a Compass software (Fountain Computer). A given model was digitalized and represented by a black-white volumetric picture so that all internal regions, corridors and passages, became black, while all outside regions were white. The three-dimensional map is splitted into the two-dimensional layers of the $3.1 \mathrm{~m}$ thickness by the same software. Next, information about spatial volumetric scales related to a single pixel (voxel) were calculated, since it depends upon the scale at which a map was rasterized into pixels. For the three-dimensional Wind, and Lechuguilla Caves, the voxel size equals $(1.8 \times 1.8 \times 3.1) \mathrm{m}^{3}$, and $(2.3 \times 2.3 \times 3.1) \mathrm{m}^{3}$, respectively. Thus, the spatial scales of actual numerical images are comparable. The investigated map dimensions (in pixels) were equal to, $(1256 \times 663 \times 65)$, and $(1276 \times 663 \times 162)$, for the Wind, and Lechuguilla Caves, respectively. The numerical procedure of random walk is carried out with the use of the following main steps:

I. A random choice of the starting point (a black pixel) for a walk,

II. A walk with the 6 equally possible single step, for the assumed number of time of repetitions,

III. A calculation of a distance launched,

IV. A repetition of the experiment, in 1000 times, with the same starting point chosen in step I,

V. Calculation of the average distance launched during the above steps of II-IV,

IV. A choice of the another starting point, at random, and the repetition of the experiment for 1000 times - the repetition of II-V steps leads to the another value of averaged distance.

The mentioned steps are described below in details.

A virtual random movement starts from a randomly chosen black pixel on the digital image of the cave. There are only six options that can be performed for the next step in the three-dimensional experiment - left, right, forward, backward, up, and down. The walk can be repeated 
many times $(\sim 1000)$ for the chosen starting pixel, and the resultant distances are averaged to provide a single mean value. Time of a walk, expressed by the number of trials, can be varied beginning from a rational minimum of $1 / 15$ of the number of layers creating the three-dimensional representation of caves, for example, it was equal to 4 (the approximation of $65 / 15$ ) for in the Wind case. The maximum values of trials were $1 / 2$ part of the number of layers creating the three-dimensional representation of caves, for example $65 / 2 \approx 33$ for in the Wind case. The choice of trials warrants a linear dependence between averaged squared distance and numbers of trials, while the slope of this dependence reveals the unique information about a cave network. A given random experiment is repeated for different randomly chosen points -5000 repetitions provides enough amount of information - and the results are presented as distribution of the slopes.

In general, such statistical experiments reveal the property, known from literature (Mandelbrot, Ness 1968), that an averaged squared random-walk distance increases naturally with the time scale $t$ (represented here by the assumed number of random walk steps) in the following manner

$$
<r^{2}>=A t^{2 H}
$$

where $\left\langle r^{2}\right\rangle$ is the squared averaged distance obtained from repeated trials, $A$ is a constant of no importance for our analysis, and $H$ is the self-similarity exponent or the so called Hurst exponent. From the statistical perspective the Hurst exponent is an indicator of structural complexity and the type of correlation between subsequent random walks. For the $\mathrm{H}<0.5$ regime walks are negatively correlated, meaning that after a step in a given direction the next step is the same direction is less probable than in the back direction. For the $\mathrm{H}>0.5$ regime walks are positively correlated, meaning that after a step in a given direction the next step is the same direction is highly probable. The $\mathrm{H}=0.5$ case is the purely random walk with all steps of equal probability or lack of correlations between them.

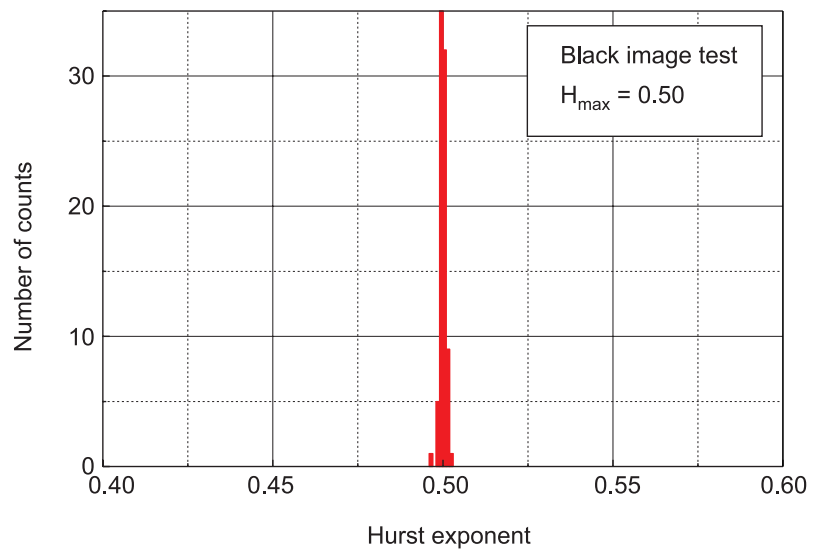

Fig. 1. The black image test performed inside a rectangle of 3448 pixels x 3696 pixels size. The self-similarity exponent was determined as the very narrow peak with maximized value positioned at 0.50
For example, for the random walk taking place on a black rectangle, $H$ equals 0.5 (Fig. 1 ) and then Eq. 1 simplifies to $\left\langle r^{2}\right\rangle=A t$. However, in general, the square root of $\left\langle r^{2}\right\rangle$ scales in time as the power of an arbitrary $H$, namely

$$
\sqrt{ }\left(r^{2}\right)=\sqrt{ } A t^{H}
$$

and thus, after calculating the logarithm of the above we obtain

$$
\log \sqrt{ }\left(r^{2}\right)=1 / 2 \log A+H \log t \approx H \log t
$$

Thus, after the simple logarithmic operation a linear dependence between the averaged distance $\sqrt{ }\left(r^{2}\right)$ and time $t$ is accessible, while the Hurst exponent $H$ is the adequate slope of the logarithmic graphs of $\sqrt{ }\left(r^{2}\right)$ vs. time. The inverse of $H$ is equal to a so called diffusion dimension $d_{f}$ being another important parameter characterizing objects in nature. For a totally filled (black) system, without any internal spatial structure, $d_{f}$ equals 2 . Thus, Eq. 2 with $H=$ $1 / d_{f}$ can be treated as formal definition of the diffusion dimension. The diffusion dimension belongs to a set of parameters classifying fractals, e.g. fractal capacity dimension or fractal correlation dimension, and can be used to characterize objects in nature (Andreychouk et al. 2013).

The quantitative method, presented in the current paper, relies on finding a self-similarity exponent distribution unique for a given cave image. The general rule is that the more tiny details took place at a map, and the more morphologically complex cave is, then lower values of $H$ are obtainable. Values of $H$ significantly larger than 0.5 represent so called anomalous diffusion, and they are not encountered in geological objects (Feder 1988).

\section{Results and discussion}

The Hurst exponent distributions, calculated for the caves along with fitted curves (components), are given in Fig. 2. The fitting to histograms employs three Gaussian-shaped components of four different peak-positions $H_{i}$ along with their widths $w_{t}(i=1 \ldots 4)$, enabling quantitative estimation of cave complexity.

The calculated parameters are shown in Table 1. The working rule can be expresses as follows: the smaller that the value of the Hurst exponent is, and the larger the component aerial intensity (the area under a given component fitted in the histogram) is, then the more intense the morphostructural diversity takes place. This is why a first component pair of parameters $\left(H_{1}, w_{1}\right)$ distanced most away from 0.5 , can be associated with thinned structural predispositions for speleogenesis, while the fourth component pair of parameters $\left(H_{4}, w_{4}\right)$, located closely to the 0.5 value, are informative for more global predispositions. It is worth emphasizing that, the widths of fitted components can be treated as a measure of contribution of subsequent karstification factors. 

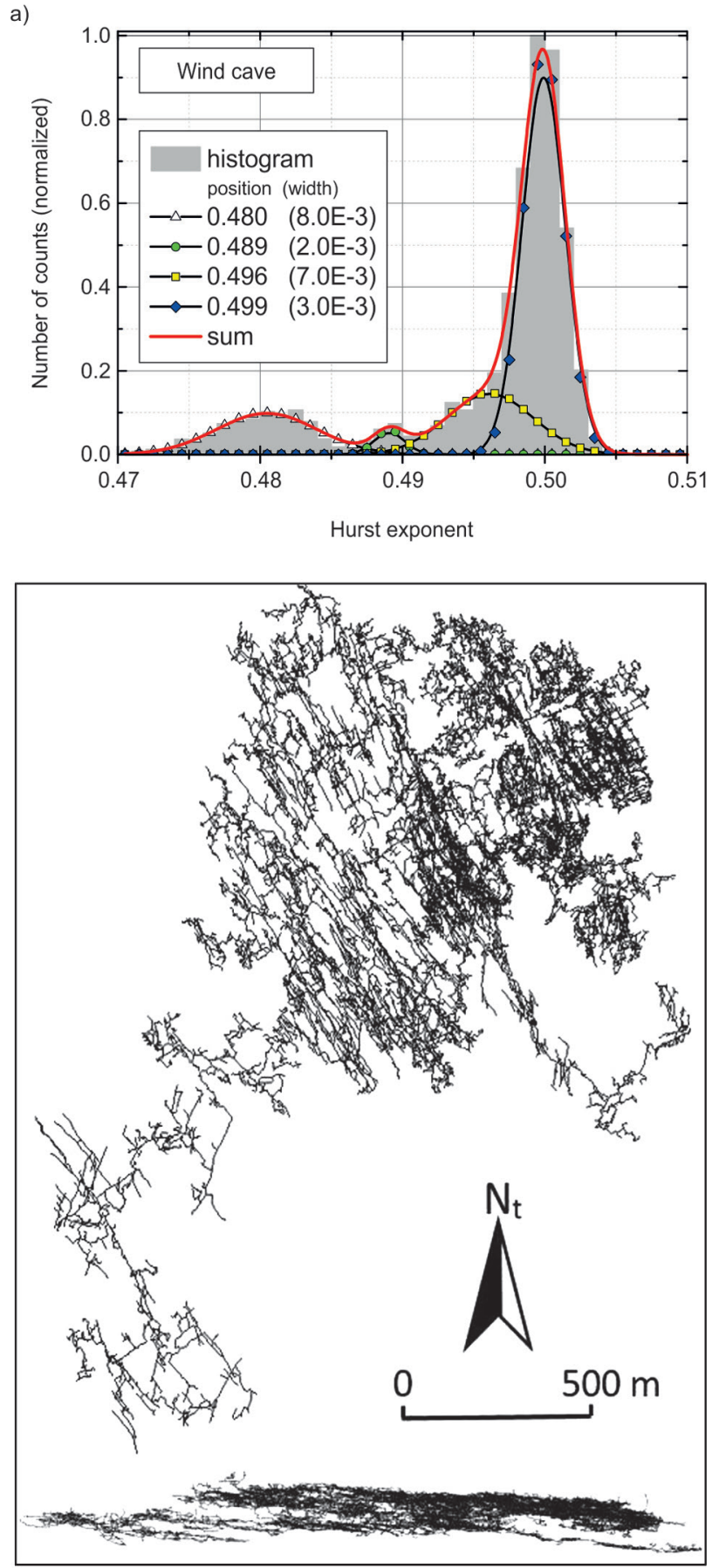

Performed calculation provided the four Hurst components equal to $0.480,0.489,0.496$, and 0.499 . Hence, the 0.499 component significantly prevails over the others. It is indicative for non-correlated, random processes involved in morphogenesis. As examples, for the Wind Cave it may be the action of hydrothermal water and for the Lechuguilla Cave the impact of water enriched with sulphur acid. Additionally, both Wind and Lechuguil- b)
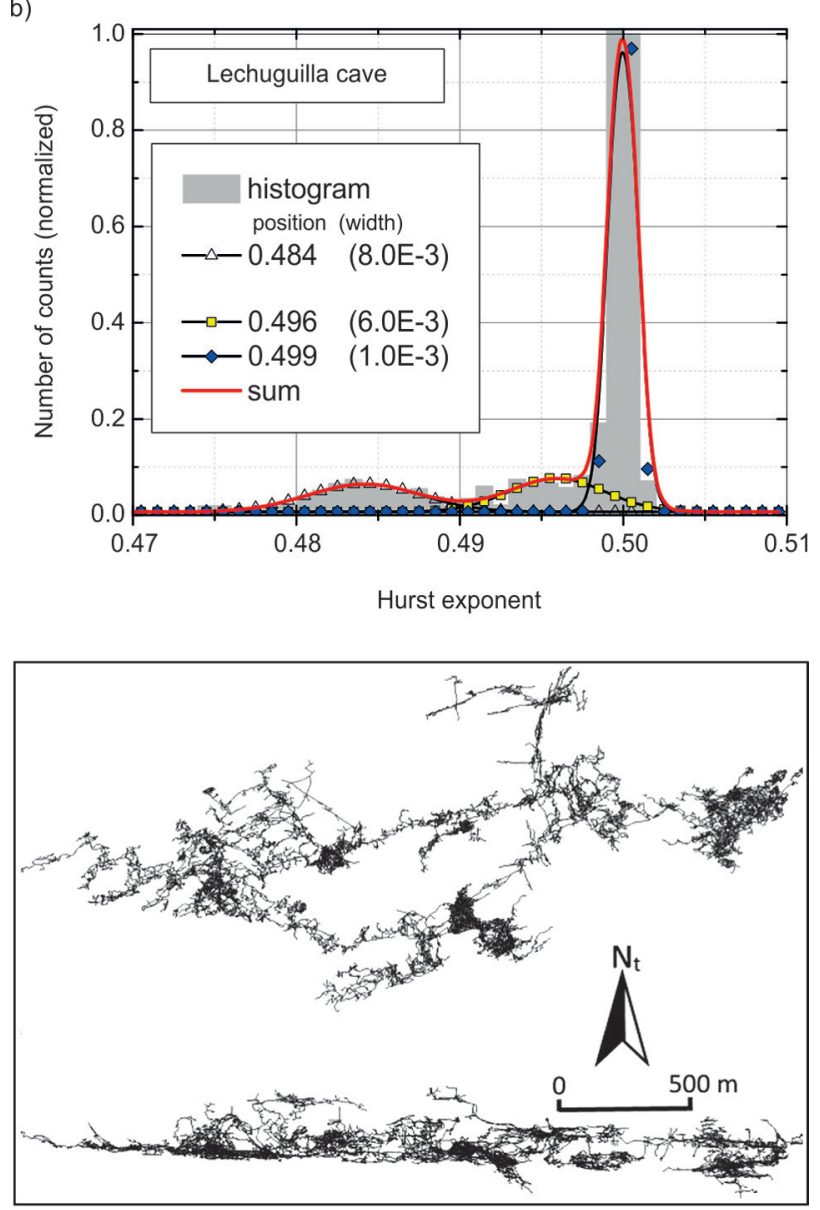

Fig. 2. The Hurst exponent distributions for the Wind Cave (a), and the Lechuguilla Cave (b). The dominating 0.499 component is characteristic for very random network system. The width of lines reflects a three-dimensional passages density which is higher for Wind Cave

la caves, have long, complex speleogenetic history, the different processes are overprinted on one another (Levy 2007, Palmer 2011). All these circumstances produce a 'noisy' structural diversity.

In other words, the structural complexity of the three-dimensional caves is very diversified and the level of this diversity can be expressed by relevant location of Hurst exponents. Importantly, the values of all Hurst ex-

Table 1. Parameters of Hurst exponent histograms (Fig. 2): positions of components maxima and its widths (FWHM)

\begin{tabular}{lcccccccc}
\hline \multirow{2}{*}{ Cave } & \multicolumn{3}{c}{ Hurst exponent at maximum } & \multicolumn{4}{c}{ Full width at half-maximum } \\
\cline { 2 - 10 } & $H_{1}$ & $H_{2}$ & $H_{3}$ & $H_{4}$ & $w_{1}$ & $w_{2}$ & $w_{3}$ & $w_{4}$ \\
\hline Wind Cave & 0.480 & 0.489 & 0.496 & 0.499 & 0.008 & 0.002 & 0.007 & 0.003 \\
Lechuguilla Cave & 0.484 & - & 0.496 & 0.499 & 0.008 & - & 0.006 & 0.001 \\
\hline
\end{tabular}


ponents for the Wind and Lechuguilla Caves are placed relatively closer to the 0.5 value.

The comparison of calculations (parameters in the Table 1 and Fig. 2) show that Wind Cave seems to be more deterministic from structural predispositions point of view $\left(H_{1}=0.480, H_{2}=0.489\right)$ than Lechuguilla Cave $\left(H_{1}\right.$ $=0.484, H_{2}=0$ ). The structural control of its morphology is better visible, than in the case of Lechuguilla. This follows, probably, from the less significant transforming impact of thermal (Wind Cave) than sulphuric-acid (Lechuguilla Cave) water onto the fissures and pores of layers. A vertical character, and a relatively poor horizontal development of Lechuguilla Cave, in comparison to Wind Cave, is also reflected by a fewer number of components and its smaller width (Fig. 2).

\section{Conclusions}

The presented analysis of the morphological structure of caves with complex morphology with the use of Hurst exponent and a random walk method allowed for the quantitative description (in general) of uniformity and structural regularity of volumetric cave networks. The most informative in the presented analysis is the self-similarity (Hurst) exponent distribution, its spectral components of characteristic shapes and positions.

The distribution shape is uniquely characterized by its width and the level of its symmetry. Obtained shapes reflect the level of morphological uniformity or diversity of local structure. If cave parts are significantly different from contractual average, and their structure is more diverse, isotropic and chaotic, then the Hurst exponent distribution is more spread in values, non-uniform and can even have local maxima and minima. On the other hand, if the Hurst exponent distribution is narrower, then the cave network structure can be more ordered, anisotropic and regular.

A shift of distribution into the smaller values of Hurst exponent scale, is indicative of the existence of more localized structural features. If a distribution is shifted towards the 0.5 value, then it is characteristic for the existence of large empty spaces (halls) or the existence of very dense, random networks of closely located passages or fissures.

Despite the sophisticated structural complexity of speleological objects, we suggest that proposed numerical methodology may be useful for parameterization purposes due to introducing new quantitative parameters characterizing morphology of three-dimensional cave-mazes. As an example of the similar, quantitative characterization of cave morphology, based on image-processing, fractal dimension calculations, and the lacunarity indices, can be found in the recent review work of Kambesis et al. (2015). Obtained values of fractal dimension were equal to 2.6488, and 2.6792, for the Wind Cave, and the Lechuguilla Cave, respectively. It means the values are very similar. The lacunarity index, being a measure of gaps between material objects, was also comparable for both caves: 0.9407 , and 0.9623 , respectively. In such cases the method of random walk can be supportive for additional distinction between similar caves.

The authors believe that further research efforts are desirable to better understand speleomorphogenesis of the wider class of three-dimensional speleological systems with the use of the random walk numerical experiments and self-similarity analysis.

\section{Acknowledgements}

Rodney D. Horrocks, and the U.S. National Park Service staff are acknowledged for providing numerical data of the Wind and Lechuguilla Caves. This work was carried under the WICA-2014-SCI-005 and CAVE-2014-SCI-0014 Permits of the U.S. National Park Service. We are grateful to Larry Fish for providing Compass software (Fountain Computer) and supportive discussion about three dimensional data analysis.

\section{References}

Andreychouk V., Blachowicz T., Domino K., 2013. Fractal dimensions of cave for exemplary gypsum cave-mazes of Western Ukraine, Landform Analysis 22: 3-8. doi: 10.12657/landfana.022.001

Bakalowicz M.J., Ford D.C., Miller T.E., Palmer A.N., Palmer M.V., 1987. Thermal genesis of dissolution caves in the Black Hills, Geological Society of America Bulletin 99: 729-738. doi: 10.1130/0016-7606(1987)99<729:TGODCI >2.0.CO;2

Budge T.J., Sharp Jr. J.M., 2008. Modeling the usefulness of spatial correlation analysis on Karst systems, Ground Water 47: 427-437.

Chilès J.P., 1988. Fractal and geostatistical methods for modelling of a fracture network, Mathematical Geology 20: 631-654. doi: 10.1007/ BF00890581

Curl, R.L., 1986. Fractal dimensions and geometries of caves, Mathematical Geology 18: 765-783. doi: 10.1007/BF00899743

Du Chene H.R., Martinez R., 2000. Post-speleogenetic erosion and its effect on cave development in the Guadalupe Mountains, New Mexico and west Texas. Journal of Cave and Karst Studies 62(2): 75-79.

Feder J., 1988, Fractals, Plenum, New York.

Ford D.C., 1989. Features of the genesis of Jewel Cave and Wind Cave, Black Hills, South Dakota, Bulletin of the National Speleological Society 51: 100-110.

Garber R.A., Grover G.A., Harris P.M., 1989. Geology of the Capitan shelf margin-subsurface data from the northern Delaware Basin. In Harris, P.M. \& Grover, G.A. (eds.), Subsurface and outcrop examination of the Capitan shelf margin, northern Delaware Basin. Society of Economic Paleontologists and Mineralogists Core Workshop No. 13: 3-269.

Gulden B., 2013. World's longest caves. Geo2 Committee on Long and Deep Caves. National Speleological Society (NSS).

Havlin S., and Ben-Avraham D., 2002. Diffusion in disordered media, Advances in Physics 51: 187-292.

Hill C.A., 1987. Geology of Carlsbad Cavern and other caves in the Guadalupe Mountains, New Mexico and Texas. New Mexico Bureau of Mines and Mineral Resources Bulletin 117, 150 p.

Horrock R.D., Szukalski B. W., 2002. Using geographic information systems to develop a cave potential map for Wind Cave, South Dakota, Journal of Cave and Karst Studies 64(1): 63-70.

Kambesis, P.N., Larson, E.B., Mylroie, J.E., 2015. Morphometric analysis of cave patterns using fractal indices, in Feinberg, J., Gao, Y., and Alexander, E.C., Jr., eds., Caves and Karst Across Time: Geological Society of America Special Paper 516, p. 1-20. 
Klimchouk A.B., 2007. Hypogene Speleogenesis: Hydrogeological and Morphogenetic Perspective, Special Paper no.1., National Cave and Karst Research Institute, Carlsbad, NM, 106 pp.

Klimchouk A.B., 2009. Morphogenesis of hypogenic caves, Geomorphology 106: 100-117. doi:10.1016/j.geomorph.2008.09.013

Laverty M., 1987. Fractals in karst, Earth Surface Processes and Landforms 12: 475-480. doi: 10.1002/esp.3290120505

Levy D.B., 2007. Oxidation-reduction chemistry of Lechuguilla Cave seepage, Journal of Cave and Karst Studies 69: 351-358.

Mandelbrot B., Ness van J.W., 1968. Fractional Brownian motions, fractional noises and applications, SIAM Reviews 10: 422-437.

Maramathas A.J., Boudouvis A., 2006. Manifestation and measurement of the fractal characteristics of karst hydrogeological formations, Advances in Water Resources 29: 112-116. doi: 10.1016/j.advwatres.2005.06.003
Palmer A. N., 2011. Distinction between epigenic and hypogenic maze caves, Geomorphology 134: 9-22. 10.1016/j.geomorph.2011.03.014 Palmer A.N, Palmer M.V. (2000). Hydrochemical interpretation of cave patterns in the Guadalupe Mountains, New Mexico. Journal of Cave and Karst Studies 62(2): 91-108.

Pardo-Igúzquiza E., Dowd P.A., Xu C., Durán, J.J., 2012. Stochastic simulation of karst conduit networks, Advances in Water Resources 35: 141- 150. doi:10.1016/j.advwatres.2011.09.014

Pardo-Igúzquiza E., Durán J.J, Robledo R., Guardiola C., Luque J. A., Martos S., 2014. Fractal Modelling of Karst Conduits, Lecture Notes in Earth System Science, Mathematics of Planet Earth, Proceedings of the 15th Annual Conference of the International Association for Mathematical Geosciences, Springer Berlin Heidelberg, p. 217-220. doi: 10.1007/978-3-642-32408-6 